\title{
Costs of hospitalization due to underlying disease or its complications in children with cerebral palsy.
}

\author{
Bahare Yaghmaie ${ }^{1}$, Shaghayegh Cheshmkhorooshan ${ }^{2}$, Reza-Shervin Badve ${ }^{3}$, Alireza Tavasoli ${ }^{3}$, \\ Gholamreza Zamani $^{3}$, Mahmoodreza Ashrafi ${ }^{4}$, Mahmood Mohamadi ${ }^{4}$, Bahar Allahverdi ${ }^{*}$ \\ ${ }^{1}$ Pediatric Critical Care Subspecialist, Children's Medical Center, Pediatric Center of Excellence, TUMS, Iran \\ ${ }^{2}$ Children's Medical Center, Pediatric Center of Excellence, TUMS, Iran \\ ${ }^{3}$ Pediatric Neurologist, Children's Medical Center, Pediatric Center of Excellence, TUMS, Iran \\ ${ }^{4}$ Department of Pediatric Neurology, Children's Medical Center, Pediatric Center of Excellence, TUMS, Iran \\ ${ }^{5}$ Pediatric Gastroenterologist, Research Center For Pediatric Gastroenterology and Hepatology, Children's Medical \\ Center, Pediatric Center of Excellence, TUMS, Iran
}

\begin{abstract}
Background: Cerebral palsy is considered a neurological disorder and taking care of children with cerebral palsy is costly for their families. We evaluated the costs and complications of hospitalization, hoteling, treatment, paraclinic for children with cerebral palsy referring to Children's Medical Center in 2012. This study was an attempt to estimate the expenditures required for children with $\mathrm{CP}$ and to take a new attitude toward their lifetime quality.

Methods: This retrospective cross-sectional study was conducted on 97 patients diagnosed with cerebral palsy and admitted in children's Medical Center in 2012. Data were gathered from the archives of the hospital. These data includes patients demographic characteristics like age, gender, causes of hospitalization, duration of hospitalization, total costs, treatment costs, paraclinical costs like echocardiography, tests, EEG, ECG, radiology and hoteling costs. The gathered information was analysed with SPSS, version 20 . $P$ value $<0.05$ was considered significant.

Results: The mean cost attributed to hoteling, paraclinic, treatment and total costs were 5,276,865 Rials, $2,020,075$ Rials, 2,496,668 Rials and 11,751,818 Rials, respectively. The average number of hospitalizations was $1.59 \pm 1.45$ with a maximum of 10 admissions in one year. The average duration of hospitalization in one year was $14.81 \pm 12.23$ with minimum and maximum of one and $91 \mathrm{~d}$. The average of total costs per year was $48,396,556 \pm 25,267,167$.

Conclusions: Evaluation the costs associated with this disorder would be helpful in determining required budget and facilitating the lifetime quality of patients and their families.
\end{abstract}

Keywords: Cerebral palsy, Hospitalization costs, Pediatrics, Lifetime quality.

Accepted on October 30, 2017

\section{Introduction}

Cerebral palsy is the most common motor disability in childhood. The term refers to a group of permanent disorders of the development of movement and posture, leading to activity restriction, that are attributed to non-progressive disturbances that occurred in the developing fetal or infant brain (1). Depending on which areas of the brain are affected, $\mathrm{CP}$ is classified to four main types: 1 . the most common type of CP is spastic CP (stiff muscles) that involves about $80 \%$ of patients with CP. Increased muscle tone and awkward movements in this type are evident; 2 . Dyskinetic CP involves $10-15 \%$ of people with CP. In this type the movements are uncontrollable and muscle tone changes (varying from too tight to too loose); 3. Ataxic CP involves $5 \%$ of cases with $\mathrm{CP}$. Cerebellum damage is the cause of ataxia (poor balance and coordination); 4. Some patients have symptoms of spasticdyskinetic CP. In addition to motor disorders in children with cerebral palsy, sensory and cognitive impairments, seizure and behavioral problems are manifested [1-3].

Investigations from Western Australia, Sweden, the United Kingdom and the United States have informed cerebral palsy rates of between 2.0 and 2.5 per 1,000 live births [4-7]. While the total number of children with $\mathrm{CP}$ has remained constant [3] or increased since 1970 [5-7], there has been a regular rise in the risk of cerebral palsy related to preterm and post-term infants [4-9]. UCP (United Cerebral Palsy) and CDC (Centers 
for Disease Control and Prevention) estimated that around 8,000 to 10,000 babies and infants are diagnosed per year with cerebral palsy $[10,11]$. Nowadays the treatments that are implemented by multidisciplinary teams to improve body movements in patients with $\mathrm{CP}$ include physical therapy, orthopedic surgery, seizure control medications, BOTOX injection and hydrotherapy $[2,12]$.

The patients with cerebral palsy require long-term supportive care or services. Taking care of children with cerebral palsy is difficult and costly for their families Average lifetime costs per person estimated at $\$ 921,000$ for persons with CP The costs include: direct nonmedical costs (costs of home and vehicle modifications, special education) $(9.2 \%)$; direct medical costs (physician visits, inpatient hospital stays, medications, assistive devices) (10.2\%); Indirect costs (value of productivity losses in workplaces and households) $(80.6 \%)[13,14]$. The frequent and occasionally long hospitalization of the patients due to the underlying disease or its complications impose a huge burden on their family `s shoulder.

Regarding incomplete investigations concerning hospitalization costs (treatment, paraclinic, hoteling), especially in our country, in this study we aimed to evaluate the cost of hospitalization due to the underlying disease or its complications in children with cerebral palsy referring to Children's Medical Center in 2012. Total costs and hospitalization costs based on sex and age were measured. This evaluation can be helpful for preparation of essential facilities and estimation of approximate costs.

\section{Patients and Methods}

\section{Patients}

This retrospective cross-sectional study was conducted on 97 patients with $6.32 \pm 4.24$ y old diagnosed with cerebral palsy and admitted in children's Medical Center in 2012. Simple sample selection method with regard to the previous studies was used for determination of sample size.

\section{Inclusion and exclusion criteria}

Patients with cerebral palsy based on paediatrician's diagnosis and the one that hospitalized in children's Medical Center in 2012 due to underlying disease or it's complications were entered into the study. On the other hand, patients without cerebral palsy, causes of hospitalization except underlying disease or its complications and incompetency of patient's information file were excluded from this study.

\section{Performance}

The files related to patients with inclusion criteria in 2012 were investigated and data were gathered from the archives of the hospital. These data includes patients demographic characteristics like age, gender, causes of hospitalization, duration of hospitalization, total costs, treatment costs, paraclinical costs like echocardiography, tests, EEG, ECG, radiology and hoteling costs. It should be noted that some hospitalized patients in 2012 were just suspected CP and weren't old enough to be diagnosed definitely. If the diagnosis was approved in the coming years, these patients would be entered into the study. The gathered data were entered into SPSS software version 20 and then were analysed.

\section{Ethical consideration}

The study was carried out in accordance with the Declaration of Helsinki, the ethics committee of the Kermanshah University of Medical Sciences approved the protocols of the study. The patients were informed about the procedure of the study and written consent was provided. Also, patients were free to leave the study whenever they want.

\section{Data analysis}

Qualitative and quantitative data were analysed and reported as frequency $(\%)$ and mean \pm standard deviation, respectively. $\mathrm{P}$ value $<0.05$ was considered significant. The gathered information was analysed with SPSS, Version 20. The descriptive statistics index which includes prevalence, distribution and dispersion were calculated.

\section{Results}

In this survey, 97 patients hospitalized in children`s Medical Center during 2012, with average of $6.32 \pm 4.24$ y old were studied. The oldest and the youngest patients were $18 \mathrm{y}$ old and one day-old baby boy, respectively. Figure 1A represents dispersion distribution of studied population based on age. 44 of patients $(45.5 \%)$ are female and 53 of them $(54.6 \%)$ are male (Figure 1B). The average days of hospitalization were $7.69 \pm 10.74$. Minimum and maximum duration was 1 and 91 $\mathrm{d}$, respectively (Figure 1C).

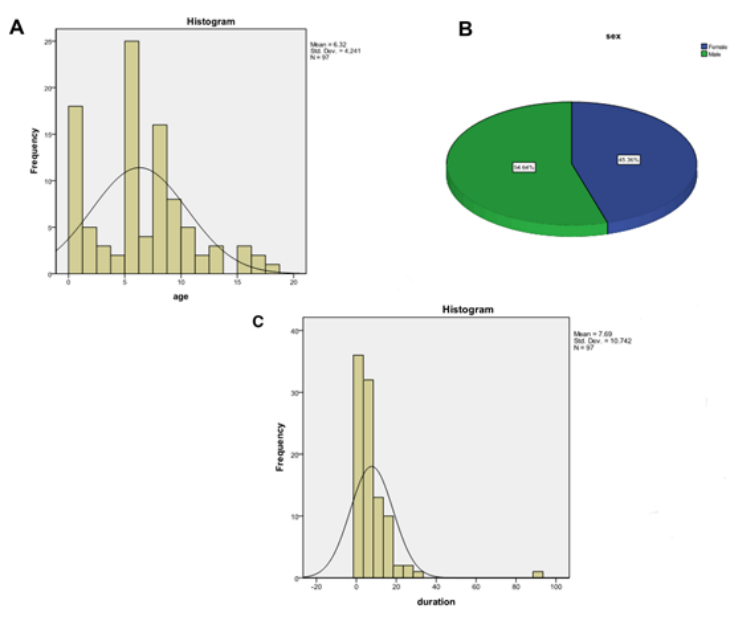

Figure 1. (A) Dispersion distribution based on age; (B) Frequency distribution based on sex; (C) Population distribution based on duration of hospitalization.

Table 1 represents causes of hospitalization. The most common cause of patient hospitalization was seizures (44. 3\%). Other common diagnosis were deformity (19.6\%), pneumonia 
(8.2\%), IVIg administration (4.1\%) and aspiration pneumonia $(3.1 \%)$. In 6 cases, cause of hospitalization was not identified.

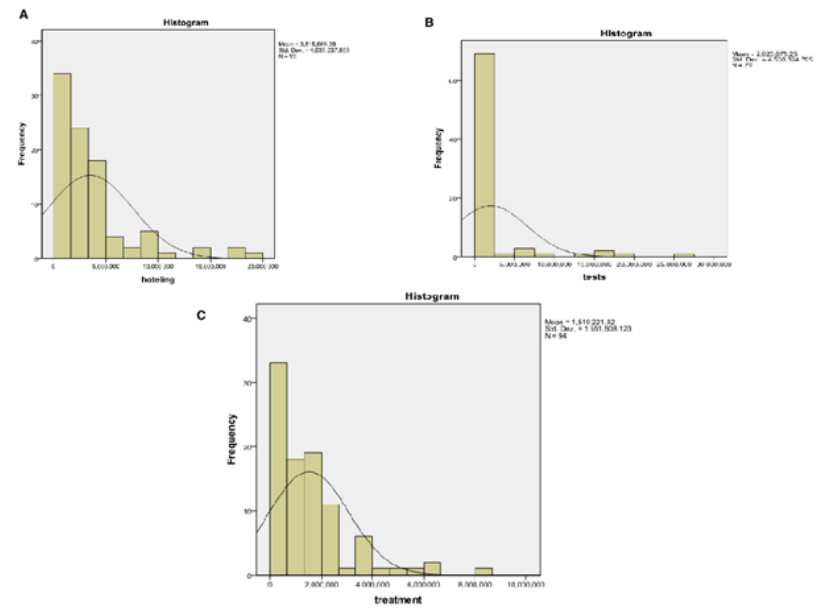

Figure 2. (A) Dispersion distribution of hoteling costs; (B) Dispersion distribution of paraclinical costs; (C) Dispersion distribution of treatment costs.

Table 1. Causes of hospitalization.

\begin{tabular}{|c|c|c|c|}
\hline Diagnosis & Frequency & Percent & Cumulative percent \\
\hline Not Identified & 6 & 6.2 & 6. 2 \\
\hline Aspiration pneumonia & 3 & 3. 1 & 9.3 \\
\hline $\begin{array}{ll}\begin{array}{l}\text { Central } \\
\text { catheterization }\end{array} & \text { Vein }\end{array}$ & 1 & 1. 0 & 10. 3 \\
\hline Deformity & 19 & 19. 6 & 29. 9 \\
\hline Dyspnea & 1 & 1. 0 & 30.9 \\
\hline Dystonia & 1 & 1. 0 & 32. 0 \\
\hline Fever & 1 & 1. 0 & 33. 0 \\
\hline Failure to thrive & 1 & 1. 0 & 34.0 \\
\hline GERD+seizure & 1 & 1. 0 & 35.1 \\
\hline GTC & 3 & 3. 1 & 38. 1 \\
\hline GTC+HUS & 1 & 1. 0 & 39. 2 \\
\hline Hydrocephaly & 1 & 1 & 40.2 \\
\hline IVIg administration & 4 & 4. 1 & 44. 3 \\
\hline Metabolic disturbance & 1 & 1. 0 & 45.4 \\
\hline Muscle biopsy & 1 & 1. 0 & 46. 4 \\
\hline Neuropathy & 1 & 1. 0 & 47.4 \\
\hline Pneumonia & 8 & 8. 2 & 55.7 \\
\hline PO intolerance & 1 & 1. 0 & 56.7 \\
\hline Seizure & 38 & 39. 2 & 95.9 \\
\hline Shunt infection & 1 & 1. 0 & 96.9 \\
\hline Shunt malformation & 1 & 1. 0 & 97.9 \\
\hline
\end{tabular}

\begin{tabular}{llll}
\hline Urinary Tract Infection & 1 & 1.0 & 99.0 \\
\hline Z-plasty & 1 & 1.0 & 100.0 \\
\hline Total & 97 & 100.0 & \\
\hline
\end{tabular}

The mean cost attributed to hoteling, paraclinic, treatment and total costs were 5,276,865 Rials, 2,020,075 Rials, 2,496,668 Rials and 11,751,818 Rials, respectively (Figure 2).

Taking multiple hospitalizations of one patient into account, a total of 61 patients were studied. The average number of hospitalizations was $1.59 \pm 1.45$ with a maximum of 10 admissions in one year. The average duration of hospitalization in one year was $14.81 \pm 12.23$ with minimum and maximum of one and $91 \mathrm{~d}$. The average of total costs per year was $48,396,556 \pm 25,267,167$.

\section{Discussion}

Assessment about costs over the lifespan of individuals with cerebral palsy is limited. In the decade 1990-2000 costs of cerebral palsy were evaluated twice in United States, in 1992 (the costs was estimated $\$ 503,000$ per case) [15] and in 1994 [16]. In 2000 the average cost of services used by the young adults with hemiplegia CP was calculated $£ 12500$ annually [17]. In 2007 Hoving et al. evaluated 40265 Euro as the costs for children with severe CP per annum in Germany [18]. In 2006 another investigation concerning cost of hospitalization, in-patient hospital utilization of children with CP was done. Data about 37,000 children with CP that hospitalized in 1997 were analysed. The expenditure was about 600 million dollars. Children with CP manifested longer lengths of stay (6.3 vs. 4.1 d, $\mathrm{p}<0.001)$, higher total costs $(16,024$ vs. 9952 dollars, $\mathrm{p}<0.001)$, more diagnosis $(5.6 v s .3 .0, \mathrm{p}<0.001)$ and more procedures $(1.7$ vs. $1.1, \mathrm{p}<0.001)$ per admission. Patients with CP were transmitted to other facilities $(\mathrm{p}<0.001)$ or prescribed home health care $(\mathrm{p}<0.001)$ upon discharge. Therefore, hospitalization of children with $\mathrm{CP}$ demonstrates a huge expenditure for health care systems. Statistical studies in order to improve the management of conditions and prediction of the costs associated with $\mathrm{CP}$ could facilitate children and their family's situation and decrease charge of the hospitalization [19]. In 2009 a study on lifetime costs of cerebral palsy was conducted in Denmark. Of those individuals with CP, 2367 ones who were born in 1930 to 2000 and were alive in 2000, were analysed. The lifetime costs were divided into three categories: health care costs, productivity costs, and social costs. The lifetime cost of CP was about $€ 860000$ for men and about $€ 800000$ for women. The largest component was social care costs, especially during childhood. Including adults with $\mathrm{CP}$ in the labor market would have a beneficial effect on the lifetime costs of CP. The measurement of lifetime costs of $\mathrm{CP}$ should be considered to evaluate quality of life in children and adults with CP as the main target [20]. Care improvements in United States have caused enhanced survival of children with Neurological Impairment (NI). Children with NI which includes cerebral palsy account for a fundamental proportion of inpatient resources expended in US and their impact is 
growing. Therefore allocating budgets to these impairments is challenging [21].

Considering the incomplete investigations about hospitalization costs (treatment, paraclinic, hoteling), especially in our country, in this study we aimed to evaluate the cost of hospitalization due to the underlying disease or its complications in children with cerebral palsy referring to children`s Medical Center in 2012. We divided direct medical costs associated with patients to 3 groups: hoteling costs, paraclinical costs, treatment costs. Eventually we calculated total inpatient hospital costs. The average cost of hospital bed and caregiver hospital stay for all the admitted population in 2012 were calculated 5,276,865 Rials. The average cost of paraclinic which includes echocardiography, tests, radiology, EEG (electroencephalogram), ECG (electrocardiogram) for the total population was evaluated 2,020,075 Rials in 2012 and finally average total cost of hospitalization in studied population was reported $11,751,818$ Rials. If we calculate inflation rate based on increase of dollar price, estimated costs for hoteling, paraclinic, treatment and total costs would be 11,609,103 Rials, 4,444,165 Rials, 5,492,669 Rials, and $25,853,999$ Rials, respectively. In mentioned study that was conducted in 2006, cost of hospitalization per person, amounted to 16024 dollars for children with cerebral palsy [19]. According to dollar rate that was 9220 Rials in 2006, the estimated cost would be 147,741,280 Rials. If we calculate inflation rate based on increasing of dollar price, the mentioned number equals 528,792,000 Rials in 2012 that is much higher than the one evaluated in present study. In addition, through an investigation in Denmark, hospital costs of patients with $\mathrm{CP}$ were estimated about $€ 52,000$ [20]. According to Euro rate that was 13,500 Rials in 2009, the estimated cost would be $702,000,000$ Rials. With consideration of the inflation rate the mentioned number equals 1,638,000,000 Rials in 2012. Therefore costs of hospitalization and total costs between previous studies and the present study are extremely different. It should be noted that the data were gathered and were evaluated from the patients that were admitted into public hospital. Thus the costs would be different compared to freestanding children's hospitals.

On the other hand, adequate levels of Physical Activity (PA) and physical fitness provide psychological and physiological advantages [22,23]. An active life optimizes patient's physical performance in daily life especially in individuals with $\mathrm{CP}$ [24], since patients with CP have low levels of physical fitness [25-28] and high amount of sedentary time [29]. Therefore performing a lifestyle intervention for the patients with $\mathrm{CP}$ might be cost-effective or cost-saving rather than represent no intervention to enhance physical behavior and fitness [30].

\section{Conclusion}

In conclusion, cerebral palsy is a costly disorder imposing a huge burden on families of the patients and the health care system, as well. Evaluation the costs associated with this disorder would be helpful in determining required budget and facilitating the lifetime quality of patients and their families.
The present study attempted to estimate expenditures but further research is required for better outcomes.

\section{References}

1. Rosenbaum P, Paneth N, Leviton A, Goldstein M, Bax M, Damiano D. A report: the definition and classification of cerebral palsy April 2006. Develop Med Child Neurol Suppl 2007; 109: 8-14.

2. OShea TM. Diagnosis, treatment, and prevention of cerebral palsy. Clin Obstetr Gynecol 2008; 51: 816-828.

3. Meamarian A, Ashrafi Esfahani S, Mehrpisheh S, Mahdavi Saeedi A, Aghakhani K. Evaluation of the anatomical position of the vermiform appendix in Iranian cadavers in 2013: brief report. Tehran Univ Med J TUMS Publ 2015; 73: 221-225.

4. Stanley FJ, Watson L. Trends in perinatal mortality and cerebral palsy in Western Australia, 1967 to 1985. BMJ 1992; 304: 1658-1663.

5. Murphy CC, Yeargin-Allsopp M, Decoufle P, Drews CD. Prevalence of cerebral palsy among ten-year-old children in metropolitan Atlanta, 1985 through 1987. J Pediatr 1993; 123: 13-20.

6. MacGillivray I, Campbell DM. The changing pattern of cerebral palsy in Avon. Paediatr Perinat Epidemiol 1995; 9: 146-155.

7. Hagberg B, Hagberg G, Olow I. The changing panorama of cerebral palsy in Sweden. VI. Prevalence and origin during the birth year period 1983-1986. Acta Paediatrica 1993; 82: 387-393.

8. Moster D, Wilcox AJ, Vollset SE, Markestad T, Lie RT. Cerebral palsy among term and postterm births. JAMA 2010; 304: 976-982.

9. Mardasi FG, Galehdari H, Khatami S, Majdinasab N. Association Study between Multiple Sclerosis Disease and HLA DQA0102* 1 in South-West Iran. Focus on Sciences 2016; 2.

10. Rosenbloom L. Diagnosis and management of cerebral palsy. Arc Dis Childhood 1995; 72: 350-354.

11. Reddihough DS, Collins KJ. The epidemiology and causes of cerebral palsy. Aust J Physiother 2003; 49: 7-12.

12. Beukelman D, Mirenda P. Augmentative and alternative communication: Supporting children and adults with complex communication needs. Brookes Publ 2005.

13. Centers for Disease C, Prevention. Economic costs associated with mental retardation, cerebral palsy, hearing loss, and vision impairment-United States 2003. MMWR Morbid Mortal Weekly Rep 2004; 53: 57-59.

14. Merenstein D, Egleston B, Diener-West M. Lengths of stay and costs associated with childrens hospitals. Pediatrics 2005; 115: 839-844.

15. Control C, Prevention. Economic costs of birth defects and cerebral palsy-United States, 1992. MMWR Morbid Mortal Weekly Rep 1995; 44: 694. 
16. Waitzman NJ, Romano PS, Scheffler RM. Estimates of the economic costs of birth defects. Inquiry J Med Care Organiz Provis Financ 1994; 31: 188-205.

17. Beecham J, ONeill T, Goodman R. Supporting young adults with hemiplegia: services and costs. Health Soc Care Commun 2001; 9: 51-59.

18. Hoving M, Evers S, Ament A, Van Raak E, Vles J. Intractable spastic cerebral palsy in children: a Dutch cost of illness study. Develop Med Child Neurol 2007; 49: 397-398.

19. Murphy N, Hoff C, Jorgensen T, Norlin C, Young P. Costs and complications of hospitalizations for children with cerebral palsy. Pediatr Rehab 2006; 9: 47-52.

20. Kruse M, Michelsen SI, Flachs EM, Bronnum-hansen H, Madsen M, Uldall P. Lifetime costs of cerebral palsy. Develop Med Child Neurol 2009; 51: 622-628.

21. Berry JG, Poduri A, Bonkowsky JL, Zhou J, Graham DA, Welch C. Trends in resource utilization by children with neurological impairment in the United States inpatient health care system: a repeat cross-sectional study. PLoS Med 2012; 9: 1001158.

22. Warburton DE, Nicol CW, Bredin SS. Health benefits of physical activity: the evidence. Canadian Med Assoc J 2006; 174: 801-809.

23. Trost S. Discussion paper for the development of recommendations for childrens and youths participation in health promoting physical activity. Aus Dep Health Ageing 2005.

24. Rimmer JH. Health promotion for people with disabilities: the emerging paradigm shift from disability prevention to prevention of secondary conditions. Phys Ther 1999; 79: 495-502.

25. Slaman J, Bussmann J, van der Slot WM, Stam HJ, Roebroeck ME, van den Berg-Emons RJ. Physical strain of walking relates to activity level in adults with cerebral palsy. Arc Phys Med Rehab 2013; 94: 896-901.
26. Nieuwenhuijsen C, Van der Slot W, Dallmeijer A, Janssens P, Stam H, Roebroeck M. Physical fitness, everyday physical activity, and fatigue in ambulatory adults with bilateral spastic cerebral palsy. Scandinavian J Med Sci Sports 2011; 21: 535-542.

27. Hombergen SP, Huisstede BM, Streur MF, Stam HJ, Slaman J. Impact of cerebral palsy on health-related physical fitness in adults: systematic review. Arch Phys Med Rehabil 2012; 93: 871-881.

28. Balemans A, Van Wely L, De Heer S, van Den Brink J, De Koning JJ, Becher JG. Maximal aerobic and anaerobic exercise responses in children with cerebral palsy. Med Sci Sports Exerc 2013; 45: 561-568.

29. Carlon SL, Taylor NF, Dodd KJ, Shields N. Differences in habitual physical activity levels of young people with cerebral palsy and their typically developing peers: a systematic review. Disab Rehab 2013; 35: 647-655.

30. Slaman J, van den Berg-Emons R, Tan SS, Russchen H, van Meeteren J, Stam H. Cost-utility of a lifestyle intervention in adolescents and young adults with spastic cerebral palsy. J Rehab Med 2015; 47: 338-345.

\section{*Correspondence to}

Bahar Allahverdi

Pediatric Gastroenterologist

Research Center for Pediatric Gastroenterology and Hepatology

Children's Medical Center

Pediatric Center of Excellence

TUMS

Iran 